\title{
A INSTITUCIONALIZAÇÃO DA SOCIOLOGIA NO ENSINO SUPERIOR PARANAENSE'
}

\author{
Nelson Dacio Tomazi \\ Professor do Departamento de Ciências Sociais da UEL \\ E-mail: tomazi@sercomtel.com.br
}

Silvio Antonio Colognese

Professor do Centro de Ciências Humanas e Sociais da UNIOESTE

Cristina Alves dos Santos

Acadêmica do Curso de Ciências Sociais/UNIOESTE e bolsista PIBIC/CNPq

Cleber Augusto Pimenta Pastor

Acadêmico do Curso de Ciências Sociais/UEL e bolsista PIBIC/CNPq

\section{Resumo}

Procuramos apresentar os resultados preliminares da pesquisa sobre a História da Sociologia no Paraná, com ênfase particularmente no processo de sua institucionalização enquanto disciplina acadêmico-científica nas Instituições de Ensino Superior (IES). O objetivo principal é destacar a constante descontinuidade na trajetória de consolidação dos cursos de Ciências Sociais, bem como a presença tímida da Sociologia neste contexto de relações acadêmicas.

Palatras-chave: Institucionalização, Sociologia, Universidade, Paraná, História.

\footnotetext{
I Trabalho apresentado no $X$ Congresso da Sociedade Brasileira de Sociologia,
} realizado em Fortaleza-CE de 03 a 06 de setembro de 2001. 
processo de institucionalização da Sociologia no ambiente universitário compreende diferentes fases, descle a sua implantação no Brasil. Embora na literatura encontram-se sugeridas diferentes periodizações, considera-se pertinente a concepção apresentada por Liedke Filho (1990; 1992), que divide este processo em duas etapas, subdivididas em dois períodos cada:

\section{-1 "Etapa da Herança Histórico-Cultural da Sociologia"
a) Período dos Pensadores Sociais \\ b) Período da Sociologia de Cátedra}

\section{"Etapa Contemporânea da Sociologia"}

a) Período da Sociologia Científica

b) Período de Crise e Diversificação

A "primeira etapa" compreende a "Herança Histórico-Cultural da Sociologia". Nela pode-se identificar, em primeiro lugar, o "Período dos Pensadores Sociais", que se estende de meados do século XIX até o início do século XX. Nele não haviam mecanismos institucionalizados de formação e a produção de conhecimento era artesanal, caracterizada por ensaios eruditos, influenciados pela literatura sociológica e filosófica de origem européia ou norte-americana (COLOGNESE, 1998, p.23).

O segundo período é o da "Sociologia de Cátedra", iniciado com a instalação das cátedras em escolas normais, em meados da década de 1920 e posterior criação de cursos acadêmicos em Ciências Sociais no início da década de 1930. É o período em que a Sociologia implanta-se decisivamente no ambiente universitário, pela criação de cátedras, cursos de graduação em Ciências Sociais (1933 - Escola Livre de Sociologia e Política de São Paulo - ELSP; 1934 - Universidade de São Paulo -USP e outros), e a implantação pioneira da pós-graduação em Sociologia e Antropologia em 1941 na ELSP, na qual, "após o múnimo de dois anos de aulas diárias e de defesa de tese baseada em pesquisa original, o aluno fazia jus ao título de mestre em Ciências" (NOGUEIRA, 1981, p.207). 
A "segunda" é a "Etapa Contemporânea da Sociologia" e referese aos períodos da "Sociologia Científica" e de "Crise e Diversificação". O primeiro período é "caracterizado pela consolidação institucional, sob a égide do funcionalismo, de uma concepção empírico-positiva do ensino e da pesquisa em Sociologia" (LIEDKE FILHO, 1990, p.7). Nele o ensino e a pesquisa sociológicas expandiram-se, tendo em Florestan Fernandes um dos maiores expoentes na formação de uma nova geração de Sociólogos a partir da USP. Estas atividades, inspiradas na chamada Sociologia da Modernização, desenvolviam-se seguindo um "modelo de sociólogo profissional e de constituição de grupos de pesquisadores envolvidos em um trabalho comum" (LIMONGI, 1989, p.233).

O segundo é o "Período de Crise e Diversificação" da Sociologia, marcado pela crise institucional e profissional decorrentes da repressão cultural do regime militar, mas principalmente pela crise de hegemonia da Sociologia Científica e a emergência de várias outras alternativas teóricas. Neste movimento, houve um redimensionamento das pesquisas, na direção da substituição dos chamados macro-projetos, por projetos menores e mesmo artesanais. Por outro lado e, apesar desta crise, este foi o período de implantação definitiva e de grande expansão da pós-graduação stricto sensu em Sociologia, cuja consolidação se iniciou entre 1985 a 1988, concretizando-se mais amplamente durante os anos 1990 (COLOGNESE, 1998, p.27). Os reflexos desta consolidação se fizeram notar no aumento significativo de docentes titulados e de publicações na área, pulverizados nas diversas IES do País.

Apesar da pertinência desta periodização sugerida por Liedke Filho para o caso brasileiro em geral, há que se reconhecer que a sua construção está respaldada mais diretamente nos casos melhor sucedidos de institucionalização da Sociologia no contexto acadêmico, que são os de São Paulo, Rio de Janeiro e em menor escala Minas Gerais. Isto mesmo em decorrência da inexistência de uma literatura especializada, capaz de esclarecer como se deu a institucionalização da Sociologia no universo acadêmico na maioria dos outros estados brasileiros. A

\footnotetext{
2 A importância de se realizar uma investigação nacional a cerca das "sociologias locais" de cada estado foi reafirmada em 1997, durante encontro da Sociedade Brasileira de Sociologia (SBS), realizado em Brasília.
} 
existência desta lacuna nas investigações justifica e constitui a maior motivação para a realização de pesquisas sobre as "sociologias locais" de cada estado. Este trabalho inscreve-se neste processo de construção de conhecimento ${ }^{2}$ concentrando-se sobre o caso do Paraná. O objetivo principal é destacar que, apesar da relativa proximidade geográfica em relação a São Paulo, por exemplo, a trajetória de institucionalização da Sociologia foi bastante diversificada no ensino superior paranaense, caracterizando-se pela constante descontinuidade na consolidação dos cursos de graduação em Ciências Sociais e pela presença tímida da Sociologia neste contexto de relações acadêmicas.

Mesmo levando em conta a periodização da institucionalização da Sociologia em termos brasileiros pensamos que ao analisar o caso paranaense, no ensino superior, alguns fatores específicos justificam uma periodização diferenciada: o relativo isolamento da Sociologia no Paraná (desde o seu surgimento em 1938 na UFPR, até o final dos anos 50) em relação ao desenvolvimento da Sociologia em outros estados; a descontinuidade na trajetória de consolidação dos cursos de Ciências Sociais; a presença tímida da Sociologia no contexto das relações acadêmicas; a falta de interação entre os sociólogos ligados as IES públicas paranaenses, gerando ilhas em cada escola e poucos grupos de pesquisa com trabalho integrado.

Resumidamente: a "primeira fase", "Implantação cla Sociologia", viria a partir da criação do curso de graduação em Ciências Sociais, em 1938, na UFPR, até o final da década de 60, e se caracterizaria como a fase de implantação do primeiro curso no estado, de criação de uma cátedra de Sociologia mas principalmente, da insegurança e crise para afirmar a Sociologia no ambiente universitário, já que existia um isolamento da Sociologia em relação aos desenvolvimentos ocorridos em outros estados, além da carência de pesquisas na área e de uma liderança proeminente da Antropologia no contexto das ciências sociais da UFPR.

A "segunda fase", "Expansão das Ciências Sociais", do final dos anos 60 à metade da década de 80 , compreende uma maior expansão dos cursos de Ciências Sociais e uma maior constituição de grupos docentes dedicados ao ensino e à pesquisa sociológica (principalmente na UFPR e ainda precariamente na UEL), além de gradualmente se esta- 
belecer um maior contato com os desenvolvimentos que ocorriam principalmente na Sociologia paulista; mesmo assim, a presença da Sociologia no contexto acadêmico ainda é tímida.

A "terceira fase", "Crise da Sociologia 'particular' e Novas Perspectivas", da segunda metade dos 80 até os dias atuais, é marcada de um lado, pela crise e desativação dos cursos de Ciências Sociais nas IES privadas, mas também, pela implantação de novos cursos de graduação no final dos anos 90 , pela consolidação dos grupos dedicados à pesquisa e ao ensino, pela implantação da pós-graduação lato e stricto sensu, e pela busca de uma melhor organização da categoria profissional no Paraná3.

\section{Descontinuidade e fraca institucionalização na trajetória da sociologia no contexto universitário paranaense}

A presença das Ciências Sociais em geral e da Sociologia em particular no contexto acadêmico paranaense foi relativamente precoce, aproximando-se da própria temporalidade no ensino superior do País. Ela remonta a criação da Faculdade de Filosofia, Ciências e Letras do Paraná, em fevereiro de 1938, constituída inicialmente de "professores das Faculdades de Direito, Engenharia e Medicina da Universidade do Paraná, da Escola Agronômica do Paraná, alguns membros do Círculo de Estudos Bandeirantes, sacerdotes católicos e outros" (WESTPHALEN, 1988, p.19). A Faculdade organizou-se inicialmente em três departamentos (Filosofia, Ciências e Letras) e um Instituto Superior de Educação. Os primeiros cursos autorizados a funcionar naquele semestre foram os de Filosofia, Ciências Químicas, Geografia e História, Ciências Sociais e Políticas e o Curso Superior de Educação, cada um com vinte (20) vagas iniciais, embora no total ingressaram apenas dezenove (19) alunos naquele primeiro ano.

\footnotetext{
A Lei $n{ }^{\circ}$ 6.888, de 10 de Dezembro de 1980, que reconheceu a profissão do sociólogo, só foi regulamentada pelo Decreto n. ${ }^{\circ}$ 89.531, de 05 de Abril de 1984. Hoje se propõe uma reformulação da lei, levando em conta as alterações no mercado de trabalho e una melhor demarcação do espaço onde o sociólogo atua com outras profissões.
} 
Assim, a introdução das Ciências Sociais no ensino superior paranaense ocorreu já a partir de 1938, com a criação do curso de graduação, sendo que para a cadeira de Sociologia ficou designado como regente o professor Omar Gonçalves da Mota, primeiro diretor na diretoria provisória da Faculdade ${ }^{4}$. Devido a problemas financeiros e de adaptação à legislação, a manutenção da Faculdade passou, após negociação, a ser de responsabilidade da União Brasileira de Educação e Ensino, dos Irmãos Maristas ${ }^{5}$, a partir de 1939, passando os docentes indicados para as disciplinas a ser considerados catedráticos fundadores das respectivas cadeiras. Com isso, o professor Omar Gonçalves da Mota passou a ser o primeiro catedrático da cadeira de Sociologia no Paraná, bem como o titular até a sua extinção em 1962. Já o professor José Loureiro Fernandes assumiu a cátedra de Antropologia e Etnografia e Manuel de Lacerda Pinto a de Política nesta mesma data. Em 1942, Bento Munhoz da Rocha também atuaria como professor de Sociologia, embora fosse titular da cadeira de História da América (WESTPHALEN, 1988).

No bojo destas mudanças, o curso de graduação passou a ser denominado simplesmente de Ciências Sociais e reconhecido pelo Decreto Federal número 5.756, de junho de 1940, sendo que apenas um aluno colou grau junto com a primeira turma de formandos da Faculdade em 1940. Finalmente, em 1946, com a restauração da Universidade do Paraná pelo Governo Federal, a Faculdade de Filosofia, Ciências e Letras foi integrada a mesma, tendo sido eleito José Loureiro Fernandes (catedrático de Antropologia e Etnografia) para fazer parte do Conselho Universitário. Enfim, a trajetória inicial das Ciências Sociais em geral e da Sociologia em particular no ensino superior paranaense, confundese com as incertezas e descontinuidades que marcaram o período inicial da Faculdade de Filosofia, Ciências e Letras, tendo se prolongado para além da federalização da Universidade em 1950, até a conquista de uma sede própria e definitiva em agosto de 1958.

4 As informações relativas ao curso de Ciências Sociais da UFPR estão baseadas principalmente em Westphalen (1988).

5 Em Curitiba, os Irmãos Maristas, mantém a Pontifícia Universidade Católica (PUC/PR), na qual foi posteriormente implantado o segundo curso de Ciências Sociais do Paraná, em 1957. Isto por que, em 1946, com a restauração da Universidade do Paraná, a Faculdade de Filosofia foi integrada à mesma 
Este período que se estende de 1938 até o final da década 1960 pode ser considerado a primeira fase do processo de institucionalização das Ciências Sociais em geral e da Sociologia em particular no ensino superior paranaense. Trata-se de uma fase de insegurança e crises permanentes, em que as demandas institucionais internas, para a sobrevivência e consolidação da referida Faculdade, concentravam a maioria das atenções. No contexto das Ciências Sociais, apesar da permanência da cátedra de Sociologia, a liderança de José Loureiro Fernandes, catedrático de Antropologia e Etnografia, foi decisiva para que esta área assumisse uma visibilidade mais forte e se desenvolvesse com maior consistência que a Sociologia. Tanto que no início de 1948 o professor lançou o primeiro boletim da Faculdade, com resultados de pesquisas realizadas em sua cátedra. Além disso, na área desta cátedra, foi criado em 1955, o "Centro de Pesquisas Arqueológicas - CEPA, que foi um centro nacional de pesquisas de Arqueologia Pré-Histórica, de renome internacional pela presença de cientistas e pesquisadores, como Wesley Hurt e o casal Pierre e Annette Emperaire" (WESTPHALEN, 1988, p.39). Enquanto isso a cátedra de Sociologia permanecia praticamente sem visibilidade e produção científica e, aparentemente distante dos avanços que se verificavam especialmente nas Sociologias Paulista e Carioca no período. Uma explicação provável para esta situação era "a falta de auxiliares de ensino. Não há assistentes em muitas das cátedras fundamentais da Faculdade de Filosofia, mas simples instrutores, em situação muito inferior a de assistentes" (PINTO; CARNEIRO, 1955, p. 104 apud MATAR, 2000). ${ }^{6}$

Esta crise e insegurança refletiam-se em termos do número de alunos inscritos e formados pelo curso de Ciências Sociais nesta primeira fase. Tanto que até 1950 haviam sido inscritos apenas dezessete alunos no curso, sendo que de 1939 a 1942 e de 1946 a 1949 não houveram inscriçôes de novos alunos no curso. A partir de 1951 este número foi crescendo gradativamente, chegando a quarenta e oito (48) alunos inscri-

\footnotetext{
6 De acordo com uma docente da época, a dificuldade era maior por que a Faculdade contava quase exclusivamente com os seus próprios formados para assumir estas funções. Raramente docentes de outros estados eram atraídos para lecionar Sociologia em Curitiba. No máximo vinham proferir palestras e cursos rápidos (MATTAR, 2000)
} 
tos em 1959 (apesar do número de alunos dos demais cursos também não ser expressivo). Quanto ao número de formandos em Ciências Sociais, até o ano de 1959, vinte (20) alunos haviam sido licenciados e vinte e nove (29) formaram-se bacharéis. Portanto, nesta primeira fase as Ciências Sociais ficaram restritas a uma única instituição de ensino superior no Paraná, onde enfrentou uma situação de crise e insegurança constantes para a sua institucionalização. Apesar destas dificuldades, nela construíram-se as bases que propiciaram os desenvolvimentos posteriores.

Este esforço de criação das bases para a constituição de uma efetiva comunidade de sociólogos no Paraná é reconhecido por Amaral Fontoura, que destaca a liderança do professor Euclides de Mesquita na área da Sociologia da Universidade do Paraná que, inclusive, "promoveu com êxito o $1^{\circ}$ Congresso de Sociologia do Paraná" (FONTOURA, 1966, p.195). Neste sentido, no início desta fase, Oracy Nogueira reconhece que, "No Paraná, começa a se fazer notar um grupo de estudiosos de Sociologia: Euclides de Mesquita, Maria Olga Mattar e Altiva Palhana" (NOGUEIRA, 1981, p.217). Paralelo a esta constituição do campo sociológico, a Antropologia mantinha sua liderança no campo das Ciências Sociais. Assim, "No grupo de Antropologia, encabeçado por José Loureiro Fernandes e, por algum tempo, integrado por Fernando Altenfelder Silva, já se distinguia Aryon Dall'Igna Rodrigues, que posteriormente se projetaria em Linguística e, em Historiografia, Maria Cecília Westphalen" (NOGUEIRA, 1981, p.217).

Nesta fase há também a criação de um outro curso implantado pela Pontifícia Universidade Católica do Paraná - PUC/PR, em 1957, também em Curitiba. Reconhecido em 1959, o curso oferecia as mesmas opções daquele da UFPR, ou seja, Licenciatura e Bacharelado. Este curso não teve inspiração ou motivação muito distinta daquele da UFPR, até mesmo pelo fato de anteriormente o da UFPR ter sido conduzido por um breve período pelos irmãos maristas, sendo que eles haviam constituído a PUC/PR.

A "segunda fase" no processo de institucionalização das Ciências Sociais em geral e da Sociologia em particular no ensino superior paranaense se inicia no final da década de 1960 e vai até a metade dos anos 1980. É marcada pela expansão dos cursos de graduação em Ciências Sociais e pela formação gradativa de grupos de docentes 
dedicados ao ensino e a pesquisa sociológica. A expansão dos cursos de graduação e a constituição de grupos de docentes dedicados ao ensino e a pesquisa sociológica, favoreceram o estabelecimento de intercâmbios, ampliando significativamente os contatos com outras IES e a produção científica a nível nacional. Apesar disto, a interação entre os Sociólogos que atuam nas IES paranaenses permaneceu incipiente, o que não favoreceu a sua organização e a consolidação de uma produção científica característica.

Em termos de cursos de graduação em Ciências Sociais, esta segunda fase é de expansão, com a criação de quatro novos cursos. Foram implantados cursos no Norte do Estado, conforme segue: Faculdade de Filosofia, Ciências e Letras de Arapongas - (FAFICLA), em 1968, apenas com a habilitação para a licenciatura; Centro de Estudos Superiores de Londrina - (CESULON), em 1972, também com a habilitação única para a licenciatura; e na Universidade Estadual de Londrina - (UEL), em 1973, com as habilitações para a licenciatura e mais tarde o bacharelado. ${ }^{7}$

Em 1973, dois anos após a criação da UEL e na efetiva implantação desta, são implantados vários cursos novos, entre os quais, o curso de Ciências Sociais. A proposta inicial da UEL era criar apenas o então curso de Estudos Sociais, conforme preconizava o governo federal e era aceito pelo novo e primeiro reitor da UEL. Para fazer frente à imposição do governo militar, vários professores da então nova universidade, e tendo um sociólogo como Vice-Reitor, o professor Iran Martins Sanches, propuseram a criação também do curso de Ciências Sociais, o que foi feito no mesmo ano, como um possível contraponto a esta investida.

A primeira grade curricular proposta para o curso, foi um esforço basicamente do Vice-Reitor e da então professora Marcolina Tomazini, que após analisarem várias estruturas curriculares (USP, UNB, PUC-SP, UNB, UFPR), conseguiram aprovar uma de acordo com o sistema de créditos. O curso, nesse momento, era noturno e tinha apenas a opção para a Licenciatura, apesar de prever a obtenção do grau de bacharel para

'Deixamos de analisar com mais informações os cursos da FAFICLA e do CESULON porque eles foram extintos no final da década de 1980 e os dados e informações que possuímos ainda são incompletos. 
quem dispensasse as disciplinas pedagógicas. Essa preocupação maior com a formação de professores para o ensino médio permanece até hoje. Os professores sociólogos eram poucos no início, mas gradativamente foram sendo contratados vários com formação em ciências sociais.

Na medida em que o curso se consolidava, ocorreram várias mudanças pontuais na grade curricular com maior ênfase em questões teóricas nas três disciplinas básicas (Sociologia, Antropologia e C. Política) a partir da contratação de professores formados em Ciências Sociais.

Iniciando em meados dos anos 70 e mais especificamente nos anos 80 e 90 houve uma demanda muito grande da disciplina de Sociologia para vários cursos que estavam sendo implantados e se consolidando na UEL, o que exigiu a contratação de mais docentes para o departamento como também houve uma preocupação em qualificar este corpo docente, o que resultou em uma política programada de licenças para pós-graduação.

Esta trajetória do curso, com contratações seguidas e com a preocupação de qualificação fez com que houvesse uma ligação mais estreita com São Paulo, mais particularmente com a USP no início e depois também com a UNICAMP e PUC/SP. Os professores saíam de Londrina e iam fazer a pós-graduação em São Paulo. Já os professores que eram contratados via concurso, vinham de vários lugares de São Paulo, mas normalmente com a pós-graduação em São Paulo. Poucos eram de Curitiba, Belo Horizonte, Porto Alegre ou do Rio de Janeiro. Esta ligação maior com as Ciências Sociais de São Paulo, em detrimento de Curitiba, também contribuía para não se criar laços mais próximos entre as Ciências Sociais do Paraná.

Apesar da expansão, ressalta-se que ela ainda pode ser considerada relativamente tímida, na medida em que ela se deu apenas em direção à Região Norte do Estado e pelo fato de apenas dois dos novos cursos ofertarem a habilitação para o bacharelado (PUC e UEL), o que diminui as possibilidades de criação de um ethos profissional e o desenvolvimento da pesquisa científica na área. De qualquer forma, primeiro Curitiba e num segundo momento Londrina, passam a figurar como os pólos de formação e desenvolvimento da comunidade de sociólogos no Paraná, especialmente em torno das instituições públicas (UFPR e UEL). 
Em termos de institucionalização, esta segunda fase é marcada também pelo fim da cátedra de Sociologia que havia na UFPR, ocupada pelo professor Omar Gonçalves da Mota no período de 1938 a 1962, e a implantação dos primeiros departamentos na área de Ciências Sociais". Neste sentido, mesmo antes da Reforma Universitária, "os professores José Loureiro Fernandes e Cecília Maria Westphalen, desde 1959, envidaram esforços para a fundação, respectivamente, dos Departamentos de Antropologia e História, com vista ao desenvolvimento de projetos de pesquisa. Foram aprovados e criados somente em 1960" (WESTPHALEN, 1988, p.46). A partir de 1963, em função da Lei de Diretrizes e Bases, também foi criado o Departamento de Ciências Sociais, permanecendo os anteriormente implantados. Isto reforça o entendimento de que, no pólo inicial de desenvolvimento das Ciências Sociais no Paraná (Curitiba), foi a Antropologia e não a Sociologia quem alcançou maior visibilidade e exerceu a liderança acadêmica na área de Ciências Sociais nas fases iniciais, mantendo inclusive uma proximidade e afinidade significativas com a área da História. Isto Ihe possibilitou uma institucionalização mais intensa e uma produção mais significativa no contexto da Universidade Federal do Paraná também nesta segunda fase.

Tanto que a Sociologia não constituiu um Departamento específico naquele momento, ficando concentrada em torno do Departamento de Ciências Sociais. Nas demais IES que implantaram cursos de graduação na área também não se constituíram departamentos específicos de Sociologia, embora na UEL, desde o início do curso, a Sociologia vem mantendo uma presença mais significativa no contexto das Ciências Sociais, tanto em termos do número de docentes quanto do volume de disciplinas ministradas e pesquisas desenvolvidas.

A expansão do número de cursos de graduação foi acompanhada de um crescimento significativo no número de alunos inscritos e formados pelos mesmos. Apenas para ilustrar esta realidade, em 1986

\footnotetext{
* Em 1978 a professora Maria Olga Mattar foi aprovada no concurso para professor titular, na cadeira de Sociologia da UFPR. Ela se formou em Filosofia na mesma Faculdade, tendo concluído o bacharelado em 1944 e a licenciatura em 1945. Vários alunos formados pela Faculdade neste período tornaram-se docentes na mesma. em diferentes áreas do saber.
} 
haviam 298 alunos matriculados na PUC/PR, 128 na FAFICLA, 15 no CESULON, 320 na UEL e 155 alunos na UFPR.

Em relação ao número de alunos formados, por exemplo, enquanto de 1938 a 1959 a UFPR havia diplomado um total de 20 licenciados e 29 bacharéis em Ciências Sociais, entre 1960 a 1986, o número foi de cerca de 800 titulados, somados os licenciados e bacharéis (WESTPHALEN, 1988). Na UEL o número de formados de 1973 a 1986 foi de apenas 259 bacharéis e licenciados dentre 1290 matriculados no mesmo período, ou seja, apenas $20 \%$ do total, o que demonstra uma evasão altíssima.

Enfim, esta segunda fase foi de expansão das Ciências Sociais em geral e da Sociologia em particular no contexto acadêmico paranaense. Mais significativo que o número de cursos novos criados, talvez tenha sido a formação dos primeiros núcleos de sociólogos dedicados ao ensino e a pesquisa, especialmente na UFPR em Curitiba e na UEL em Londrina. É em torno destes núcleos que passam a ser desenvolvidas pesquisas, incentivada a titulação dos docentes e estreitadas as relações com os demais núcleos de ensino e pesquisa sociológicas no País. São estes núcleos que garantem a presença das Ciências Sociais e sua institucionalização no contexto do ensino superior paranaense, no período da segunda metade da década de 1980 em diante, que constitui a sua terceira fase no caso paranaense.

A "terceira fase" de institucionalização das Ciências Sociais em geral e da Sociologia em particular no ambiente acadêmico paranaense estende-se da segunda metade dos anos 1980 até os dias atuais. Esta fase caracteriza-se por uma crise das Ciências Sociais nas IES privadas, por uma expansão e consolidação de núcleos de ensino e pesquisa nas IES públicas, pela implantação da pós-graduação stricto sensu e pela busca de organização da categoria no Estado.

A crise nas IES privadas reflete a descontinuidade que se verifica nos cursos de graduação em Ciências Sociais no Paraná . Neste sentido, após a expansão em geral, verificada na fase anterior, os cursos ofertados nas IES privadas mergulharam numa profunda crise na segunda metade dos anos 1980. Esta crise pode ser percebida pela queda significativa no

"Sobre a crise dos cursos de Ciências Sociais nas IES privadas do Paraná, nos baseamos principalmente em Sanches (1992). 
número de inscrições para os concursos vestibulares que, segundo Sanches (1992), no período de 1986-1990, foi de 61,3\% na PUC/PR (passando de 142 para 55 candidatos ao curso), de $82,8 \%$ na FAFICLA (passando de 87 para 15 candidatos) e de $26,1 \%$ no CESULON (passando de 23 para 17 candidatos no vestibular). Este mesmo decréscimo é apontado pelo autor em relação ao número de matriculados nos referidos cursos que, no seu conjunto, chegou a $49,4 \%$ no mesmo período. Como resultado desta crise, os três cursos ofertados pelas IES privadas até então, foram sendo gradativamente desativados no Paraná. Assim em 1991, "Na PUC havia apenas os $2^{\circ}, 3^{\circ}$ e $4^{\circ}$ anos, na FAFICLA e no CESULON as turmas remanescentes do $4^{\circ}$ e do $3^{\circ}$ ano, respectivamente" (SANCHES, 1992, p. 158). Com o encerramento das turmas remanescentes estes cursos foram desativados, de sorte que no início dos anos 1990 restavam apenas os dois cursos de Ciências Sociais ofertados em IES públicas, em Londrina e Curitiba. E mesmo assim, os contatos e a interação entre ambos eram mínimos, não havendo relações mais institucionalizadas.

Deste modo, a crise que se abateu sobre os cursos de Ciências Sociais nas IES privadas, reflete a sua fraca institucionalização. Dedicados mais à habilitação para a licenciatura e sem a formação de grupos de docentes dedicados à pesquisa social, os cursos permaneceram isolados e não desenvolveram mecanismos de interação enquanto um campo científico específico. Neste sentido, apesar da crise, "Não se colheu nenhuma iniciativa institucional entre a PUC/PR, FAFICLA e CESULON que, em 1991, resultasse numa visão mais ampla das funções universitárias, em perspectivas de ações de integração e intercâmbio entre as instituições" (SANCHES, 1992, p.181). Assim, embora expressando a fraca institucionalização das Ciências Sociais no contexto paranaense, esta crise é localizada nas IES privadas, onde os docentes dedicam-se apenas parcialmente aos cursos, concentram-se no desenvolvimento do ensino e na habilitação para a licenciatura.

Com o encerramento das atividades dos três cursos de ciências sociais das escolas privadas, as duas públicas mantiveram o ritmo de trabalho e de consolidação dos cursos e expansão de atividades. No nível da graduação, a UEL cria em 1994 o turno matutino do curso de ciências sociais inicialmente só a licenciatura e depois também o bacharelado. 
Em outras IES públicas esta mesma fase é de expansão e de consolidação de grupos dedicados ao ensino e a pesquisa, o que se reflete na expansão dos cursos de graduação e na implantação da pósgraduação stricto sensu. Em termos de cursos de graduação, após a elaboração da carta consulta para a autorização de funcionamento pelo Conselho Estadual de Educação (CEE/PR) em 1993, sob a coordenação do Professor Silvio Antonio Colognese, finalmente foi implantado a partir de 1998 o curso de Ciências Sociais da Universidade Estadual do Oeste do Paraná (UNIOESTE), no campus de Toledo.

O curso de Ciências Sociais da UNIOESTE é ofertado em regime seriado anual e turno noturno, possibilitando a formação de bacharéis e licenciados. A primeira turma de bacharéis colará grau no final de 2001 e a de licenciados no final de 2002. O corpo docente do curso é formado por mestres e doutores titulados em diferentes das principais universidades do País, como UFRGS, USP, UnB, UFCE e UFRJ, com ligeiro predomínio da área da Sociologia em relação a Antropologia e a Ciência Política. Apesar de sua constituição recente, os docentes do curso têm se destacado pela produção científica, publicada e apresentada em congressos como os da ANPOCS, SBS e CLACSO, bem como pela participação efetiva nos esforços de institucionalização das Ciências Sociais no Paraná, como por exemplo, na organização em conjunto com a UEL, do I Congresso Estadual de Ciências Sociais realizado em Londrina no ano de 2000.

Em 2000, foi implantado o curso de Ciências Sociais na Universidade Estadual de Maringá (UEM), mas o departamento de Ciências Sociais existia desde 1976 quando foi implantada a UEM. Na estruturação então procedida, criou-se o Departamento de Ciências Sociais, vinculado ao Centro de Ciências Humanas, Letras e Artes. Este departamento resultou da fusão dos departamentos de História e de Estudos Sociais: dos quais o último congregava principalmente os professores de Sociologia que ministravam aulas em diversos cursos da UEM. Inicialmente o departamento de Ciências Sociais atendia basicamente os Cursos de História e de Estudos Sociais (Licenciatura de $1^{\circ} \mathrm{Grau}$ ).

A partir de 1988 houve o desmembramento de departamentos criando-se um de História e outro de Ciências Sociais (DCS) que permaneceu atendendo 16 cursos de graduação da UEM, num total 2.786 
alunos, oferecendo disciplinas da área de Ciências Sociais (Antropologia, Ciência Política e Sociologia) e Filosofia.

O corpo docente do departamento é composto em sua maioria de mestres e doutores, sendo que há um empenho muito grande de qualificação a nível de doutorado de todo os professores. Isso significa que ao estar no início da implantação do curso $\left(2^{\circ}\right.$ ano) já existe um corpo docente qualificado para o desenvolvimento do mesmo e mais ainda com a volta de muitos professores que estão licenciados fazendo o doutorado.

Apesar de outras IES privadas terem fechado seus cursos no período, no final dele, em 1999, foi implantado o curso de Ciências Políticas e Sociais nas Faculdades Integradas de Palmas. O curso é ofertado em regime semestral e visa a formação de bacharéis, com habilidades para a pesquisa, o magistério e a atuação profissional. Apesar das dificuldades enfrentadas pelos docentes para o exercício da pesquisa, mais comum em instituições privadas, percebe-se um esforço no sentido da integração com os demais cursos da área no Estado e o desenvolvimento da prática da pesquisa.

Findo o milênio o Paraná voltou a contar com cinco cursos de graduação na área de Ciências Sociais, com a diferença em relação à fase anterior, de que apenas um é ofertado por uma IES privada (em Palmas) sendo os demais todos ofertados por IES públicas, com as opções de habilitação para o bacharelado e a licenciatura. Esta expansão justificase em função da nova Lei de Diretrizes e Bases da Educação Nacional (LDB), que prevê a obrigatoriedade do conteúdo de Sociologia para o ensino médio, mas também do aumento da procura pelo curso nos vestibulares que, no caso da UNIOESTE, por exemplo, tem se mantido acima de dez (10) candidatos por vaga.

Por outro lado, em torno dos cursos de Ciências Sociais mais antigos nas IES públicas paranaenses, a consolidação de um corpo docente estável e titulado, dedicado ao ensino e a pesquisa, viabilizou a implantação de cursos de pós-graduação stricto sensu. Dois cursos de mestrado foram implantados a partir de meados dos anos noventa. $\mathrm{O}$ primeiro na área de Sociologia em 1995 na UFPR, seguido pelo mestrado em Ciências Sociais da UEL, implantado em 2000. Trata-se de uma implantação tardia em relação a situação nacional, onde as primeiras experiências neste sentido datam da década de 1940, tendo sido expandidas 
e intensificadas em vários estados nas décadas de 1960 e 1970 . Isto denota as dificuldades e a institucionalização tardia das Ciências Sociais em geral e da Sociologia em particular no ensino superior paranaense.

De qualquer forma, a fase atual é de consolidação da Sociologia no contexto acadêmico paranaense. Esta consolidação reflete-se ainda no aumento do número de docentes da área dedicados integralmente ao ensino e a pesquisa, no incremento significativo de seus níveis de titulação e na busca de organização e integração entre os profissionais da área. Neste sentido, destaca-se a criação do Sindicato dos Sociólogos do Estado do Paraná (SINDSOC/PR) em junho de 1985 em Curitiba. Embora constituído em sua grande maioria por profissionais da região de Curitiba e que não atuam no magistério superior, o SINDSOC/PR representa um marco no processo de consolidação da Sociologia no Paraná. Apesar de sua característica inicial, o SINDSOC/PR tem buscado uma aproximação e integração mais efetiva com os profissionais que atuam no meio acadêmico, o que se percebe, por exemplo, pela organização do IV Encontro Estadual de Sociólogos, em setembro de 1990, em conjunto com o Departamento de Ciências Sociais da UEM.

Mais recentemente merece destaque, a partir da iniciativa, principalmente, da UEL e da UNIOESTE, a organização do V Congresso Estadual de Sociólogos e do I Congresso Estadual de Ciências Sociais, em setembro de 2000 , em Londrina. Trata-se de uma tentativa de constituição da área como um efetivo campo científico, em torno das IES e seus cursos no Estado. Esta expectativa aparece explícita na apresentação do Congresso, onde se destaca que, "há 10 anos que não se realizava um Congresso Estadual. Assim, chegou o momento de se reunir para se fazer um balanço e articular atividades conjuntas entre professores e pesquisadores, formando grupos de trabalho e de pesquisa em diferentes áreas para que se possam trocar experiências, dados e resultados" 10

Para o ano de 2002, em Curitiba deverá ocorrer o II Congresso Estadual de Ciências Sociais (organizado pelos cursos de ciências sociais do Paraná) e também o XII Congresso Nacional dos Sociólogos, organizado pela Federação Nacional dos Sociólogos do Brasil (FNSB). Pensamos que estes dois eventos poderão contribuir muito para a orga-

${ }^{10}$ (http://www.uel.br/cch/eventos/congresoc). 
nização da categoria dos sociólogos bem como a integração maior dos cursos de graduação e pós-graduação no Paraná.

Enfim, a fase atual é de consolidação das Ciências Sociais em geral e da Sociologia em particular no contexto do ensino superior paranaense. Nela a Sociologia assume uma visibilidade e proeminência ligeiramente maiores em relação a Antropologia e a Ciência Política no contexto acadêmico. Contudo, trata-se de um processo em curso e que ainda encontra-se bastante distante em relação aos níveis de institucionalização da área no contexto nacional. Além disso, como o caso paranaense é marcado também pela descontinuidade na trajetória da área, ainda é cedo para arriscar uma análise sobre o seu futuro neste contexto e a consistência da consolidação que se verifica na fase atual.

\section{Considerações finais}

O processo de institucionalização da Sociologia no contexto acadêmico paranaense revela particularidades que o distinguem significativamente dos casos melhor sucedidos no Brasil. Apesar da pertinência da periodização sugerida por Liedke Filho para o caso brasileiro em geral, o relativo isolamento da Sociologia paranaense em relação aos desenvolvimentos havidos em outros estados, principalmente até o final dos anos 1950, bem como a constante descontinuidade na trajetória de consolidação dos cursos de Ciências Sociais, a falta de mecanismos permanentes de interação entre os sociólogos que atuam nas diversas IES do estado e a presença tímida da Sociologia neste contexto de relações acadêmicas, justifica a proposição de uma periodização diferenciada para a trajetória de institucionalização da Sociologia no Paraná. Trata-se de uma primeira aproximação, destinada a desafiar a comunidade acadêmica a desenvolve-la, especificá-la e criticála, a fim de que se possa conhecer mais profundamente a trajetória da Sociologia no Paraná, contribuindo no processo de pesquisa sobre as "sociologias locais" de cada estado.

Neste sentido, em função dos fatores destacados anteriormente, o processo de institucionalização da Sociologia no contexto acadêmico paranaense pode ser dividido em três fases principais. A primeira inicia- 
se com a criação do primeiro curso de Ciências Sociais no estado, em 1938, e estende-se até o final dos anos 1950. É uma fase de insegurança e crise permanentes para a afirmação dos cursos de Ciências Sociais no ambiente universitário, de relativo isolamento da Sociologia em relação aos desenvolvimentos que vinham ocorrendo em outros estados, de carência de pesquisas na área e de uma liderança mais forte da Antropologia no universo do curso de Ciências Sociais da UFPR. De qualquer forma, é uma fase importante no processo de institucionalização, principalmente pela implantação do curso de graduação em Ciências Sociais e a criação de uma cátedra de Sociologia.

A segunda fase no processo de institucionalização da Sociologia nas IES paranaenses inicia-se no final da década de 1960 e se estende até a metade da década de 1980. É uma fase marcada pela expansão dos cursos de graduação em Ciências Sociais e pela formação gradativa de grupos de docentes dedicados ao ensino e a pesquisa sociológica, especialmente no interior das IES públicas (UFPR e UEL). A criação dos departamentos de Ciências Sociais concorreu positivamente neste processo. A expansão e a constituição de grupos facultaram ainda a superação gradativa do isolamento em relação aos desenvolvimentos que vinham ocorrendo, principalmente na Sociologia paulista. Mesmo assim, a interação entre os grupos de sociólogos que atuavam nas diferentes IES paranaenses permaneceu incipiente, quando não inexistente. Além disso, enquanto na UFPR a Antropologia manteve uma liderança maior no campo das Ciências Sociais nesta segunda fase, na UEL a liderança acadêmica é ligeiramente exercida pela Sociologia neste universo. Mesmo assim, no contexto acadêmico em geral, a presença da Sociologia permanece bastante tímida.

A terceira fase no processo de institucionalização da Sociologia nas IES paranaenses estende-se da segunda metade dos anos 1980 até os dias atuais. É caracterizada principalmente pela crise e desativação dos cursos de Ciências Sociais nas IES privadas, pela implantação de novos cursos de graduação no final dos anos 1990, principalmente nas IES públicas, pela consolidação de grupos de sociólogos dedicados ao ensino e a pesquisa, pela implantação da pós-graduação stricto sensu e pela busca de organização da categoria no estado. É uma fase de afirmação da Sociologia (inclusive no interior da UFPR), que rompe definitiva- 
mente com o seu isolamento, atraindo docentes formados e titulados em diferentes estados brasileiros e abrangendo novas regiões no Estado do Paraná. Apesar desta gradativa consolidação, trata-se de um processo em curso e que ainda encontra-se bastante distante em relação aos níveis de institucionalização da Sociologia no contexto nacional. Enfim, o caso paranaense é marcado pela descontinuidade na trajetória da área e ainda é cedo para assegurar que esta consolidação e afirmação da Sociologia no contexto acadêmico paranaense são consistentes e terão continuidade na longa duração.

\section{Referências Bibliográficas}

BAETA NEVES, C. ; LIEDKE FILHO, E.D. Experiências regionais de institucionalização do ensino e da pesquisa em Sociologia: a experiência da UFRGS. Brasília : SBS, 1997

COLOGNESE. Silvio Antonio. Entre Políticas e Avaliações: a pós-graduação em Sociologia no Brasil. Cascavel : EDUNIOESTE, 1998.

CORRÊA. Mariza. História da Antropologia no Brasil: 1930-1960, testemunhos. São Paulo: Vértice, 1987.

COSTA PINTO, Luis A.; CARNEIRO, E. As Ciências Sociais no Brasil. Rio de Janeiro: CAPES, 1955.

FONTOURA. Amaral. Introdução à Sociologia. Porto Alegre : Editora Globo, 1966.

LIEDKE FILHO, Enno D. Sociologia e sociedade no Brasil e na Argentina, 19541984. Cadernos de sociologia, Porto Alegre, v.2, n.2, p. 5-50, maio 1990

Enno D. Teoria social contemporânea e ensino superior. In: MOROSINI: Marilia: LEITE, Denise (Orgs). Universidade e integração do Cone Sul. Porto Alegre: UFRGS, 1992.

LiMONGi. Fernando. A Escola Livre de Sociologia e Política em São Paulo. In: MICELI. Sérgio (Org). História das Ciências Sociais no Brasil. São Paulo : Vértice, 1989. v.1.

MATTAR, Maria Olga. Entrevista a Cristina Alves dos Santos. Curitiba, 2000. 
Maria Olga. Organização e contexto social: para entender Sociologia. Curitiba : Gráfica Ativa, 1998.

MICELI, Sérgio (Org).História das Ciências Sociais no Brasil. São Paulo : Sumaré. 1989. v.1, 2.

NOGUEIRA, Oracy. A Sociologia no Brasil. In FERRI, Mário; MOTOYAMA. Shozo (Coords). História das Ciências no Brasil. São Paulo : EPU/USP. 1979-1981.

SANCHES, Iran Martin. O curso de graduação em Ciências Sociais nats instituições particulares de ensino superior no Paraná. A situação en 1991. Londrina : UEL, 1992. mimeo

WESTPHALEN, Cecília Maria. Faculdade de Filosofia. Ciências e Letras do Paraná - 50 anos. Curitiba : SBPH, 1988.

\begin{abstract}
We search present here the preliminaries results of the research about the history of the Sociology in the Parana State (Brazil), with emphasis particularly on its institutionalization process as academic-scientific discipline in the superior institutions for education. The two major objectives is stress a constant disruption in the trajectory of consolidation of the Social Sciences graduation courses and provide an assessment of the timid presence of the Sociology in the context of academic relations.
\end{abstract}

Key-Words: Institutionalization; Sociology; University; Parana: History. 